\title{
Lower insulin clearance is associated with increased risk of type 2 diabetes in Native Americans
}

\author{
Mujtaba H. Shah ${ }^{1}$ (D) Paolo Piaggi ${ }^{1}$ (D) $\cdot$ Helen C. Looker ${ }^{1} \cdot$ Ethan Paddock $^{1} \cdot$ Jonathan Krakoff ${ }^{1} \cdot$ Douglas C. Chang $^{1}$
}

Received: 7 August 2020 / Accepted: 22 October 2020 / Published online: 6 January 2021

(C) This is a U.S. government work and not under copyright protection in the U.S.; foreign copyright protection may apply 2020

\begin{abstract}
Aims/hypothesis Impaired insulin clearance is implicated in the pathogenesis of type 2 diabetes, but prospective evidence remains limited. Therefore, we sought to identify factors associated with the metabolic clearance rate of insulin (MCRI) and to investigate whether lower MCRI is associated with increased risk of incident type 2 diabetes.

Methods From a longitudinal cohort, 570 adult Native Americans without diabetes living in the Southwestern United States were characterised at baseline and 448 participants were monitored over a median follow-up period of 7.9 years with 146 (32\%) incident cases of diabetes identified (fasting plasma glucose $\geq 7.0 \mathrm{mmol} / \mathrm{l}, 2 \mathrm{~h}$ plasma glucose $[2-\mathrm{h} \mathrm{PG}] \geq 11.1 \mathrm{mmol} / \mathrm{l}$, or clinical diagnosis). At baseline, participants underwent dual-energy x-ray absorptiometry or hydrodensitometry to assess body composition, a $75 \mathrm{~g}$ OGTT, an IVGTT to assess acute insulin response (AIR), and a hyperinsulinaemic-euglycaemic clamp to assess MCRI and insulin action $(M)$.

Results In adjusted linear models, MCRI was inversely associated with body fat percentage $(r=-0.35)$, fasting plasma insulin $(r=-0.55)$ and AIR $(r=-0.22)$, and positively associated with $M(r=0.17$; all $p<0.0001)$. In multivariable Cox proportional hazard models, lower MCRI was associated with an increased risk of diabetes after adjustment for age, sex, heritage, body fat percentage, AIR, $M$, fasting plasma glucose, 2-h PG, and fasting plasma insulin (HR per one-SD difference in MCRI: 0.77; 95\% CI $0.61,0.98 ; p=0.03$ ).

Conclusions/interpretation Lower MCRI is associated with an unfavourable metabolic phenotype and is associated with incident type 2 diabetes independent of established risk factors.

Clinical trial registration numbers: ClinicalTrials.gov NCT00339482; NCT00340132
\end{abstract}

Keywords Acute insulin response · Hyperinsulinaemic-euglycaemic clamp · Insulin clearance · OGTT · Type 2 diabetes

\section{Abbreviations \\ AIR Acute insulin response \\ ALT Alanine aminotransferase \\ EGP Endogenous glucose production \\ EMBS Estimated metabolic body size \\ 2-h PG $2 \mathrm{~h}$ plasma glucose concentration \\ FPI Fasting plasma insulin concentration \\ IDE Insulin-degrading enzyme \\ $M \quad$ Insulin-stimulated glucose disposal \\ MCRI Metabolic clearance rate of insulin \\ SWNA Southwestern Native American}

\section{Douglas C. Chang}

changdc@mail.nih.gov

1 Phoenix Epidemiology and Clinical Research Branch, National Institute of Diabetes and Digestive and Kidney Diseases, National Institutes of Health, Phoenix, AZ, USA

\section{Introduction}

Hyperinsulinaemia is a common characteristic of insulinresistant individuals and is a risk factor for type 2 diabetes [1]. Peripheral insulin concentrations are determined by insulin secretion from pancreatic beta cells and its removal through metabolic clearance $[2,3]$. Insulin clearance occurs primarily in the liver and, to a lesser extent, in kidney, muscle, and adipose tissue [4]. Impaired insulin clearance is an understudied aspect of insulin metabolism and may make an important contribution to the hyperinsulinaemia observed in at-risk populations.

The roles of insulin secretory dysfunction and insulin resistance are well-recognised in the pathogenesis of type 2 diabetes $[5,6]$, and accumulating evidence has also implicated a role for insulin clearance. Reduced insulin clearance may represent a compensatory response mechanism to preserve 


\section{Research in context}

\section{What is already known about this subject?}

- Insulin resistance and pancreatic beta cell dysfunction are established abnormalities in the pathogenesis of type 2 diabetes. In contrast, less is known about the role of impaired insulin clearance

- Limited prospective studies have assessed the association between impaired insulin clearance and type 2 diabetes

\section{What is the key question?}

- Is lower insulin clearance associated with increased risk of incident type 2 diabetes?

\section{What are the new findings?}

- Lower insulin clearance, estimated using the hyperinsulinaemic-euglycaemic clamp method, is a risk factor for development of type 2 diabetes in a Native American cohort, independent of important metabolic risk factors

How might this impact on clinical practice in the foreseeable future?

- Interventional strategies targeting insulin clearance may be useful for diabetes prevention

beta cell function in response to insulin resistance [7-10]. Alternatively, reduced insulin clearance may be the primary defect leading to hyperinsulinaemia-driven systemic insulin resistance and subsequent beta cell failure $[11,12]$. It is also possible that elevated non-esterified fatty acids, especially in the portal circulation, cause both impairment of insulin clearance and hepatic insulin resistance [13]. Despite the pathogenic importance of insulin clearance, prospective evidence examining the association between lower insulin clearance and incident type 2 diabetes remains limited. This association has been established in a Hispanic and African American study population [14] but not in Native Americans, a group highly prone to developing diabetes [15] .

In the present study, to further elucidate the role of insulin clearance in type 2 diabetes, we sought to examine the crosssectional relationships between the metabolic clearance rate of insulin (MCRI), a measure of whole-body insulin clearance, with demographics, body composition, fasting plasma insulin (FPI), and reference measures of insulin action and earlyphase insulin secretion (assessed via hyperinsulinaemiceuglycaemic clamp and IVGTT, respectively) in a large cohort of Native Americans without diabetes from a community in the Southwestern United States. Additionally, in a subset of participants followed prospectively, we examined the association of MCRI with risk of type 2 diabetes. We hypothesised that individuals with lower MCRI would: (1) have an unfavourable metabolic phenotype and (2) be at greater risk for developing type 2 diabetes independent of established risk factors including insulin action and secretion.

\section{Methods}

Study population Individuals from a Southwestern Native American (SWNA) community in Arizona, USA participated in a longitudinal study of the pathogenesis of diabetes and its complications [15]. The cohort for the current analysis was selected from volunteers who also participated in detailed, inpatient metabolic phenotyping to assess determinants of type 2 diabetes, as previously described [16]. The inpatient visit included measurement of body composition, an IVGTT, a hyperinsulinaemic-euglycaemic clamp and an OGTT to verify the absence of diabetes. These participants were healthy adults (age $\geq 18$ years) who were not taking any medications known to affect glucose metabolism, did not have type 2 diabetes at baseline, and identified as full or mixed SWNA heritage (further defined below). Women were verified to be nonpregnant with a urine pregnancy test at baseline. Following the inpatient visit, these adults were invited for outpatient research visits approximately every two years regardless of health status, at which time medical records were reviewed and an OGTT was performed to follow for progression to diabetes. To evaluate the association between MCRI with insulin action $(M)$ and acute insulin response (AIR), the earliest study visit from which the first hyperinsulinaemiceuglycaemic clamp and IVGTT were available was used for cross-sectional analysis.

Type 2 diabetes and glucose regulation status were classified based on the 2003 ADA criteria [17]. The date of diagnosis was determined from research examinations or from a review of clinical records if type 2 diabetes was diagnosed during routine medical care. Written informed consent was obtained from all participants and both studies (ClinicalTrials.gov NCT00339482; NCT00340132) were approved by the Institutional Review Board of the National Institute of Diabetes and Digestive and Kidney Diseases.

Anthropometrics and heritage Height and weight were measured using standardised procedures and used for calculation of BMI. Heritage for this particular SWNA community 
was determined by self-report and classified into those with full heritage $(8 / 8$ heritage) or those with mixed heritage $(\leq 7 / 8$ heritage) and included as a dichotomous covariate given that SWNA heritage was previously associated with greater risk of type 2 diabetes [18].

Body composition Body composition was assessed by underwater weighing with determination of residual lung volume by helium dilution [19] or by total body dual-energy x-ray absorptiometry (DPX-L; Lunar Radiation, Madison, WI). The body composition measures were made comparable using previously derived comparative equations [20] to calculate body fat percentage.

OGTT and IVGTT Volunteers underwent a $75 \mathrm{~g}$ OGTT with venous glucose measurements during baseline and follow-up visits. AIR, an estimate of early-phase insulin secretion, was measured in response to a $25 \mathrm{~g}$ IVGTT and calculated as the mean incremental plasma insulin concentration from the $3 \mathrm{rd}$ to 5 th $\min [21,22]$.

Hyperinsulinaemic-euglycaemic clamp Insulin action was assessed during a hyperinsulinaemic-euglycaemic clamp, as previously described [23, 24]. In brief, after an overnight fast, a primed, continuous i.v. insulin infusion was administered through an antecubital vein for $100 \mathrm{~min}$ at a rate of $40 \mathrm{mU} \mathrm{m}^{-2}$ body surface area $\times$ min with a variable infusion of a $20 \%$ dextrose solution to maintain glucose concentrations at approximately $5.6 \mathrm{mmol} / \mathrm{l}$. The rate of glucose required to maintain euglycaemia during hyperinsulinaemic infusion is a measure of total insulin-mediated glucose disposal, or insulin action $(M)$, and was calculated for the last 40 min of the infusion and corrected for steady-state plasma glucose level and endogenous glucose production (EGP). EGP was determined at baseline and at the end of the insulin infusion using a primed continuous infusion $(11.1 \mathrm{kBq})$ of $\left[3-{ }^{3} \mathrm{H}\right]$-glucose, calculated by the Steele equation [25]. As a measure of hepatic insulin sensitivity, per cent suppression of EGP was calculated as the percentage of change from baseline. $M$ and EGP values were normalised to estimated metabolic body size (EMBS) (fat-free mass + 17.7) [23]. MCRI was calculated as the ratio of the insulin infusion rate to the mean steady-state plasma insulin concentration and expressed as $\mathrm{mm} / \mathrm{m}^{2} \times$ min, as previously described [24, 26-29]. The assumptions in this calculation are as follows: (1) the hyperinsulinaemic infusion suppresses endogenous insulin secretion [30] particularly in insulin-resistant individuals [31] and (2) tissue clearance mechanisms do not distinguish between endogenous and infused insulin.

Analytical procedures All plasma glucose concentrations were determined by the glucose oxidase method (Beckman Instruments, Fullerton, CA) and plasma insulin concentrations by the Herbert modification [32] of the Yalow and Berson method [33] or automated analysers (Concept 4, ICN Radiochemicals, Costa Mesa, CA; Access, Beckman Instruments). Values from succeeding assays were regressed to the original RIA using comparative equations. Plasma alanine aminotransferase (ALT) was measured in the local hospital laboratory (Monarch Chemistry analyser, Instrumentation Laboratory, Lexington, MA; DADE Behring-Dimension RxL Chemistry analyser, Siemens Medical Solutions, Malvern, PA).

Statistical analysis Statistical analyses were performed using SAS software (SAS Version 9.4; SAS Institute, Cary, North Carolina). Data are presented as mean $\pm \mathrm{SD}$ or median (IQR). Variables with non-normal distributions were $\log _{10}$ transformed to meet assumptions of parametric tests. The distribution of per cent suppression of EGP remained highly skewed after transformation and was categorised into quartiles. For group comparison of participant characteristics, unpaired $t$ test (Gaussian variables), Wilcoxon rank-sum (skewed variables), or $\chi^{2}$ test (categorical variables) were used where appropriate.

Linear regression models were calculated to examine the association between MCRI and selected anthropometric and metabolic characteristics adjusted for potential confounders as indicated. Regression model fit was assessed for normality and leverage with studentised residuals. Associations between MCRI and metabolic variables were expressed by the partial Pearson's r.

Cox proportional hazards models were calculated to assess the prospective relationship between baseline MCRI and risk of incident type 2 diabetes. Participants with incomplete data on covariates were excluded. HRs were expressed for a oneSD difference in the distribution of all continuous independent variables. Covariates were selected a priori as plausible confounders based on previous studies $[1,6,16,18]$. Progressively adjusted models were described: (1) univariate; (2) adjusted for age, sex, SWNA heritage, and body fat percentage; (3) further adjusted for $M$ and AIR; (4) further adjusted for fasting plasma glucose concentration and 2-h PG; and (5) further adjusted for FPI. The proportionality of hazards assumption was assessed for each covariate by the cumulative sums of Martingale residuals [34]. Potential interactions were tested between MCRI and each covariate in relation to incident diabetes by including a multiplicative term into the Cox proportional hazards model. Mediation analysis was performed to estimate the proportion of the association between MCRI at baseline and type 2 diabetes risk that is explained by ALT as described by Lin et al [35] based on the change in regression coefficients after adding the mediator to the final multivariate model. Sensitivity analysis was restricted to individuals of full SWNA heritage. Furthermore, an additional analysis was performed using an alternate calculation of MCRI, in which basal plasma insulin 
was subtracted from the mean steady-state level to test assumptions regarding suppression of endogenous insulin production during the hyperinsulinaemic-euglycaemic clamp.

For graphical visualisation of the relationship between MCRI and the cumulative incidence of diabetes, predicted cumulative incidence functions were created at the 10th and 90th percentiles of MCRI alongside their standard errors assuming mean values for all covariates described in the fully adjusted model. A two-sided $p$ value of $<0.05$ was considered statistically significant.

\section{Results}

The anthropometric and metabolic characteristics of the study population for the cross-sectional and prospective analyses are summarised in Table 1. The mean age of participants was $29.0 \pm 6.6$ years and $40.4 \%$ were female; $75.0 \%$ identified as full SWNA heritage (i.e. $8 / 8$ ). The mean BMI and body fat percentage were $35 \pm 8 \mathrm{~kg} / \mathrm{m}^{2}$ and $33 \pm 8 \%$, respectively. There was no statistical difference for the investigated variables between the cross-sectional and prospective study sets.

Cross-sectional analysis MCRI showed no association with age $(p>0.10)$. Compared with women, men had greater baseline MCRI (median [IQR]: 261 [222-317] and 280 [227-329] $\left.\mathrm{ml} \mathrm{m}^{-2} \min ^{-1}, p=0.02\right)$. These sex-differences persisted after controlling for differences in age, heritage and body fat percentage $(p<0.01)$. Participants of full SWNA heritage had lower MCRI than those with mixed heritage (270 [225-319] and 302 [250-370] $\mathrm{ml} \mathrm{m}^{-2} \mathrm{~min}^{-1}$, $p<0.0001)$. This difference remained significant after controlling for age, sex, and body fat percentage $(p=0.04)$. Additionally, MCRI was reduced in individuals with impaired glucose regulation compared with those with normal glucose regulation (260 [222-315] and 292 [237-351] $\mathrm{ml} \mathrm{m}^{-2} \mathrm{~min}^{-1}$, $p<0.0001)$. This difference was still observed after adjustment for age, sex and heritage $(p<0.01)$ but was abolished after further adjustment for body fat percentage $(p>0.10)$. Cross-sectional group comparisons are shown in ESM Table 1.

With adjustment for age, sex and heritage, MCRI was inversely associated with body fat percentage $(r=-0.35, p$ $<0.0001$, Fig. 1a). Similar associations were seen across measures of adiposity including body weight $(r=-0.33)$ and BMI $(r=-0.34$; all $p<0.0001)$. After adjustment for age, sex, heritage and body fat percentage, MCRI was inversely associated with FPI $(r=-0.55, p<0.0001$, Fig. $1 b)$ and AIR ( $r=$ $-0.22, p<0.0001$, Fig. $1 \mathrm{c})$, and positively associated with $M$ $(r=0.17, p<0.0001$, Fig. 1d). After previous adjustments,
Table 1 Baseline anthropometric and metabolic characteristics of the study populations in the crosssectional and prospective analyses

\begin{tabular}{|c|c|c|c|}
\hline \multirow[t]{2}{*}{ Variable } & \multirow[t]{2}{*}{ Cross-sectional analysis } & \multicolumn{2}{|l|}{ Prospective analysis } \\
\hline & & Non-progressors & Progressors \\
\hline$n$ & 570 & 302 & 146 \\
\hline Age (years) & $29.0 \pm 6.6$ & $28.6 \pm 6.6$ & $29.2 \pm 6.4$ \\
\hline Sex (female), $n(\%)$ & $230(40.4)$ & $118(39.0)$ & $78(53.4)^{*}$ \\
\hline Full SWNA heritage, $n(\%)$ & $428(75.0)$ & $214(70.9)$ & $121(82.9)^{\ddagger}$ \\
\hline Body weight $(\mathrm{kg})$ & $97 \pm 25$ & $92 \pm 22$ & $105 \pm 25^{\S}$ \\
\hline BMI $\left(\mathrm{kg} / \mathrm{m}^{2}\right)$ & $35 \pm 8$ & $33 \pm 7$ & $38 \pm 8^{\S}$ \\
\hline Body fat (\%) & $33 \pm 8$ & $32 \pm 8$ & $36 \pm 7 \S$ \\
\hline Fasting plasma glucose (mmol/l) & $5.0 \pm 0.6$ & $4.9 \pm 0.5$ & $5.2 \pm 0.6^{\S}$ \\
\hline 2-h PG (mmol/l) & $7.0 \pm 1.7$ & $6.6 \pm 1.6$ & $7.7 \pm 1.7 \S$ \\
\hline Glucose regulation (normal/impaired) & $375 / 195$ & $230 / 72$ & $64 / 82^{\S}$ \\
\hline Fasting plasma insulin $(\mathrm{pmol} / \mathrm{l})^{\mathrm{a}}$ & $245(183-350)$ & $230(163-294)$ & $312(224-407)^{\S}$ \\
\hline$M\left(\mathrm{mg} \mathrm{kg} \mathrm{EMBS}{ }^{-1} \min ^{-1}\right)^{\mathrm{a}}$ & $2.68(2.27-3.37)$ & $2.84(2.44-3.59)$ & $2.36(2.00-2.71)^{\S}$ \\
\hline $\operatorname{AIR}(\mathrm{pmol} / \mathrm{l})^{\mathrm{a}}$ & $1319(824-1965)$ & $1462(1026-2196)$ & $1058(658-1736)^{\S}$ \\
\hline $\operatorname{ALT}(\mathrm{U} /)^{\mathrm{a}}$ & $37(23-58)$ & $37(24-56)$ & $33.5(21-64)$ \\
\hline Basal EGP (mg kg EMBS $\left.{ }^{-1} \min ^{-1}\right)$ & $1.93(0.26)$ & $1.93(0.26)$ & $1.91(0.24)$ \\
\hline Suppression EGP (\%) ${ }^{\mathrm{a}}$ & $85(68-100)$ & $88(71-100)$ & $79(66-92)^{*}$ \\
\hline $\operatorname{MCRI}\left(\mathrm{ml} \mathrm{m}^{-2} \min ^{-1}\right)^{a}$ & $273(223-325)$ & $282(234-332)$ & $254(211-312)^{\ddagger}$ \\
\hline
\end{tabular}


MCRI was inversely associated with ALT $(r=-0.23, p$ $<0.0001$, Fig. 1e) and there was a significant linear increase in MCRI across increasing quartiles of per cent suppression of EGP, i.e. MCRI increased with increasing hepatic sensitivity (all $p<0.02$, Fig. 1f).

Prospective analysis of the 570 participants in the crosssectional analysis, 448 had a median (IQR) of $2(1-4)$ visits with a median interval of $2.6(1.9-3.9)$ years and median follow-up time of 7.9 (4.8-11.7) years. Of the 448 participants with follow-up, 146 (32\%) incident cases of diabetes were identified. As expected, progressors were more likely to have full SWNA heritage and have greater measures of adiposity and higher concentrations of fasting plasma glucose, 2-h PG, and FPI at baseline (Table 1). MCRI was significantly lower in progressors compared with non-progressors at baseline (Table 1). In contrast, ALT levels did not differ between the two groups. In Cox proportional hazard models, all continuous variables were standardised to express their HR per one-SD difference in the independent variable to facilitate comparisons across variables. In univariate analysis, a lower MCRI was associated with an increased risk of diabetes (HR $0.76 ; 95 \%$ CI $0.66,0.88 ; p<0.001)$. This association remained independent of age, sex, heritage, body fat percentage, and established risk factors for diabetes including lower $M$ and AIR (Fig. 2 and ESM Table 2). In the final model, which included FPI as an additional covariate, the association between MCRI and diabetes risk remained significant (HR $0.77 ; 95 \%$ CI 0.61, 0.98; $p=0.035$ ). After including ALT in the previous model, the association of MCRI with diabetes risk was not retained ( $p>0.50$ ) while $M$ and AIR remained independent risk factors (both $p<0.01$ ). From mediation analysis in the fully adjusted model, it was estimated that $47.3 \%$ (95\% CI 16.9, 79.9; $p<0.001)$ of the association between MCRI and type 2 diabetes risk could be statistically explained by ALT.
Fig. 1 The relationship of MCRI with (a) body fat percentage adjusted for age, sex, and heritage, and (b-f) fasting plasma insulin (FPI), acute insulin response (AIR), insulin action $(M), \mathrm{ALT}$, and per cent suppression of EGP adjusted for age, sex, heritage and body fat percentage. $x$ - and $y$-axes in $(\mathbf{b}-\mathbf{e})$ and $y$-axis in (a) are plotted on a $\log _{10}$ scale
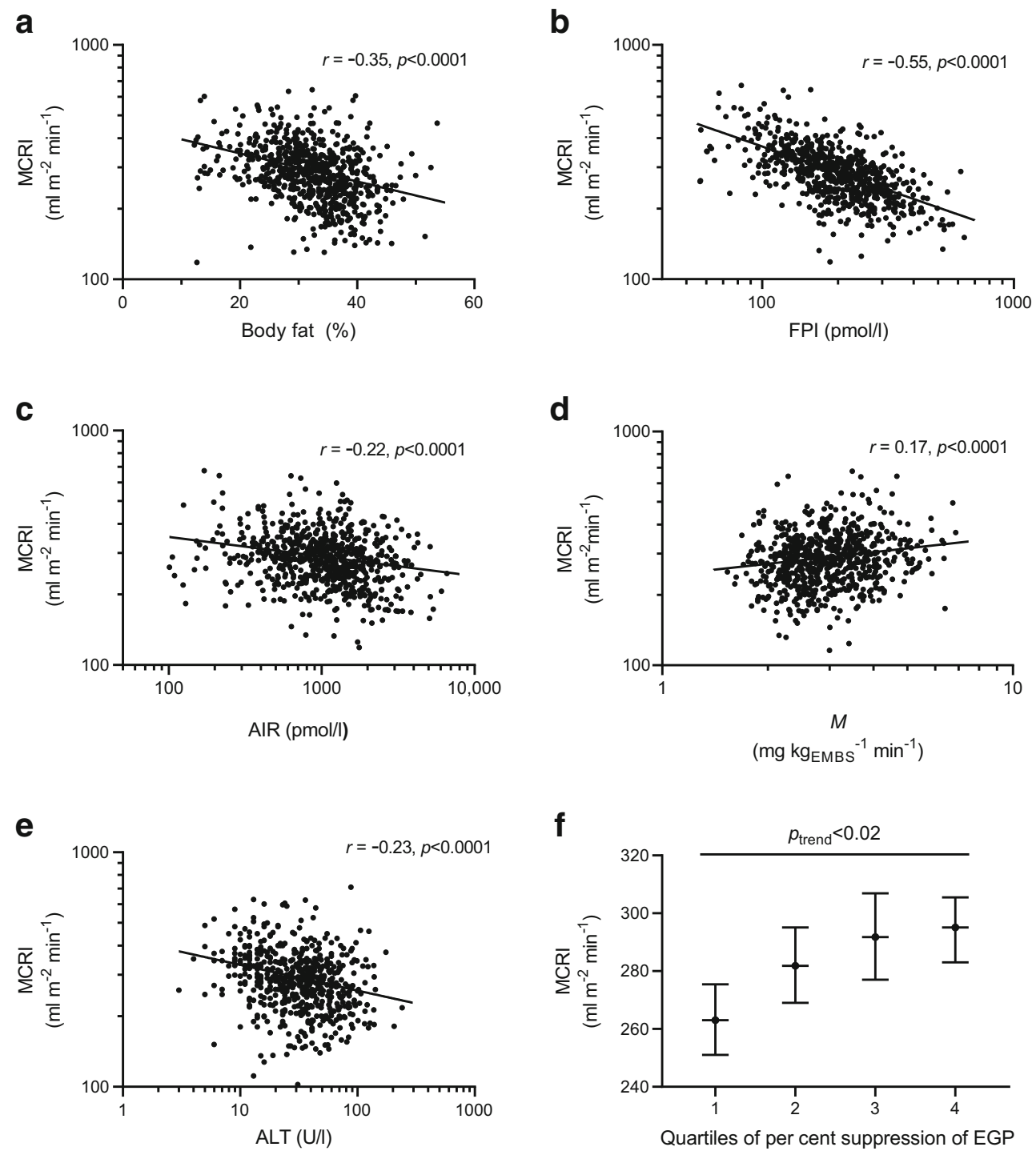


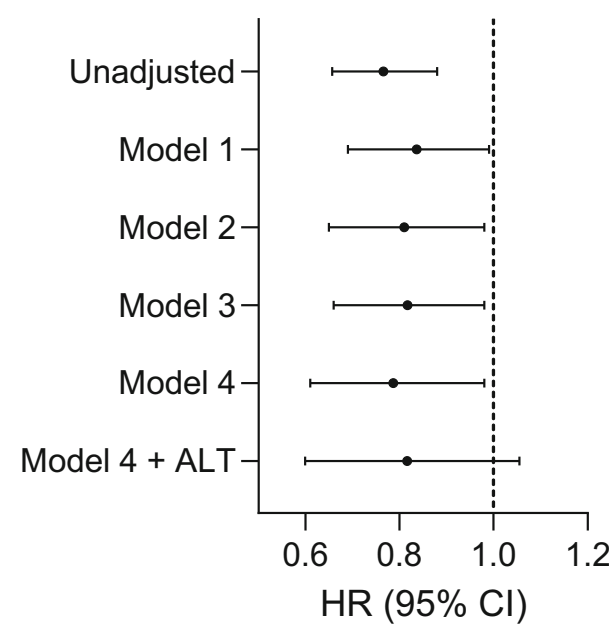

Fig. 2 Association of MCRI with incident diabetes per one-SD difference in $\log _{10}$-transformed MCRI at baseline. Model 1, adjusted for age, sex, heritage and per cent body fat; Model 2, further adjusted for $M$ and AIR; Model 3, further adjusted for fasting and 2-h PG; Model 4, further adjusted for fasting plasma insulin

No significant interaction between MCRI and any of the covariates, including sex or heritage, on incident diabetes were detected. In sensitivity analysis restricted to individuals with full SWNA heritage, the results were preserved (HR 0.76; $95 \%$ CI $0.58,0.98 ; p=0.04)$. Furthermore, in an alternate calculation of MCRI in which basal plasma insulin is subtracted from the mean steady-state level, the results remained unchanged following adjustment for all confounders included in the final model (HR 0.78; 95\% CI 0.65, 0.94; $p<0.01$ ).

As visualised in Fig. 3, participants with lower MCRI have a higher predicted cumulative incidence of diabetes than those with greater MCRI after final model adjustment.

\section{Discussion}

Cross-sectional and prospective analyses were conducted to investigate the potential prognostic role of insulin clearance in

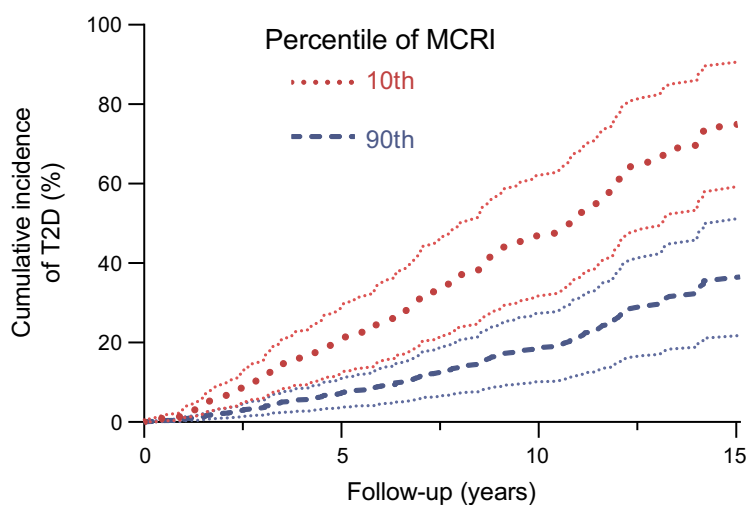

Fig. 3 Predicted cumulative incidence of type 2 diabetes (cumulative incidence $\pm 1 \mathrm{SE}$ ) at the 10th and 90th percentiles of MCRI after adjustment for age, sex, heritage, per cent body fat, $M$, AIR, fasting and 2-h PG, and fasting plasma insulin. T2D, type 2 diabetes the development of type 2 diabetes. Our cross-sectional findings indicate that lower MCRI, an estimate of whole-body insulin clearance, was associated with greater body fat percentage, elevated FPI, greater early-phase insulin secretion and lower insulin action in a cohort of healthy Native American adults. In prospective analyses, lower MCRI at baseline was associated with greater risk of incident diabetes. This association was found to be independent of established risk factors including adiposity, insulin secretion and insulin action. Collectively, these findings provide prospective evidence to support the hypothesis $[11,12]$ that impaired insulin clearance has an independent pathogenic role in the development of type 2 diabetes in humans.

In the setting of insulin resistance, individuals exhibit hyperinsulinaemia to overcome reduced insulin action and maintain normal glucose tolerance. This compensatory response involves not only increasing insulin secretion from the pancreas but also reducing the metabolic clearance of insulin. Lower insulin clearance has been observed in insulin resistance related disorders including the metabolic syndrome [36], polycystic ovary syndrome [37], fatty liver disease [38], and obesity [28]. Furthermore, differences in insulin clearance may account for the fasting and postprandial hyperinsulinaemia commonly observed among ethnic groups at increased risk for type 2 diabetes [11, 39, 40]. In agreement with these findings, we demonstrated that increased insulin resistance (indicated by elevated FPI and lower $M$ ) and greater insulin secretion (higher AIR) are independently associated with lower MCRI.

Our findings of higher whole-body insulin clearance in men relative to women contrast with previous reports of an opposite relationship [41] or no sex-differences [14, 42, 43]. In the former study, insulin was infused based upon fat-free mass, so differences in clamp study design may account for this discrepancy.

Previous work in animal models [10] and humans [7, 8] suggests that, during the insulin-resistant state, insulin clearance is reduced before insulin secretion is changed to relieve physiological demand on $\beta$ cells and minimise insulin secretory dysfunction. It is also possible that a primary defect in insulin clearance may lead to peripheral hyperinsulinaemia and ensuing insulin resistance thereby increasing risk for diabetes. In the present study, we observed that elevated ALT (a biomarker of fatty liver) and lower hepatic insulin sensitivity are associated with lower MCRI. Recent studies have recognised various markers that are associated with insulin clearance including uric acid [44], ALT [14, 43], and HDL-cholesterol [36]. Others have shown increased intrahepatic fat assessed via magnetic resonance spectroscopy is associated with lower insulin clearance [29] and that lower insulin clearance can induce isolated hepatic insulin resistance leading to steatosis through upregulated de novo lipogenesis [45]. It has also been demonstrated that elevated plasma non-esterified fatty acids, as might be seen in individuals with obesity, can reduce insulin clearance without increasing insulin secretion [46]. 
Insulin clearance involves receptor-mediated uptake of insulin and degradation by insulin-degrading enzyme (IDE) and lysosomal enzymes in hepatocytes or insulin-sensitive peripheral cells [3]. While underlying cellular mechanisms are unclear from our study, lower hepatic IDE activity but not concentrations of IDE or carcinoembryonic antigen-related cell adhesion molecule 1 (a transmembrane glycoprotein which mediates insulin endocytosis) may partially explain the reduced insulin clearance in ethnic groups at greater risk for diabetes [39].

Earlier studies conducted in this cohort of Native Americans have demonstrated the important contributions of declining insulin action and insulin secretory dysfunction in the pathophysiology of type 2 diabetes $[6,16]$. In the current study, prospective analyses revealed that lower MCRI at baseline was associated with incident type 2 diabetes; moreover, this finding was independent of these established abnormalities. These observations are in agreement with Lee et al [14], wherein insulin clearance, estimated using the frequently sampled IVGTT, was demonstrated to be a risk factor for type 2 diabetes. In further analysis, we assessed the role of ALT, a previously identified risk factor for type 2 diabetes in this population [47], as a link between lower insulin clearance and progression to diabetes. ALT mediated the MCRIdiabetes association, suggesting differences in the extent of fatty liver as a metabolic factor affecting insulin clearance.

The strengths of this study include a well-characterised prospective cohort of Native Americans, a group at high risk of developing diabetes. Moreover, there was sufficient followup for cases of incident diabetes to permit adjustment for important confounders including insulin action and insulin secretion, which were measured using reference methods. Nevertheless, the findings should be considered in the context of some limitations. First, the clamp-derived estimate of MCRI assumes complete suppression of endogenous insulin secretion during the insulin infusion period. Unfortunately, we did not have Cpeptide concentrations to assess the degree of residual insulin secretion and there may be considerable interindividual variability in suppression. To address this limitation, an analysis with an alternate calculation of MCRI assuming the opposite extreme (i.e. insulin was not suppressed at all) was conducted and yielded similar results. While this may be an overestimation of true MCRI values, these findings make it less likely that the availability of C-peptide concentrations would have affected the association of lower MCRI and type 2 diabetes. Second, the MCRI estimates represent whole-body insulin clearance and, although the majority of insulin is believed to be cleared by the liver during the hyperinsulinaemic-euglycaemic clamp, first-pass hepatic insulin extraction could not be specifically estimated, so it is unknown whether reduced first-pass extraction is more important than reduced whole-body clearance. Third, while different methods can estimate insulin clearance [48], these approaches could not be applied in this cohort because measurements were lacking. Fourth, given that most volunteers did not have repeat measurements of insulin clearance at a regular interval prior to diabetes progression, longitudinal changes were not assessed in the current study so it is unclear how insulin clearance might have changed before diabetes was diagnosed. Lastly, though the pathophysiology of type 2 diabetes in this Native American cohort mirrors that of other populations, it is unclear if this estimate of whole-body insulin clearance would be associated with incident type 2 diabetes in other populations.

In summary, lower insulin clearance in Native Americans without diabetes was associated with an unfavourable metabolic phenotype including greater body fat percentage, impaired glucose regulation, increased FPI and lower insulin action. Insulin clearance and secretion were inversely related, suggesting these two processes coordinate to maintain normal glucose tolerance. Importantly, lower insulin clearance can be regarded as a risk factor for development of type 2 diabetes independent of established metabolic abnormalities. Interventional strategies aimed at improving insulin clearance may be useful for diabetes prevention in at-risk populations.

Supplementary Information The online version contains peer-reviewed but unedited supplementary material available at https://doi.org/10.1007/ s00125-020-05348-5.

Acknowledgements The authors thank the volunteers and clinical staff of the Phoenix Epidemiology and Clinical Research Branch. Parts of this study were presented as an oral presentation at the 36th Scientific Sessions of The Obesity Society at ObesityWeek, Las Vegas, Nevada, 3-7 November 2019.

Data availability The datasets analysed during the current study are not publicly available for reasons of privacy but are available from the corresponding author on reasonable request.

Funding This work was supported by the Intramural Research Program of the National Institutes of Health, National Institute of Diabetes and Digestive and Kidney Diseases (funding number DK069015-36).

Authors' relationships and activities The authors declare that there are no relationships or activities that might bias, or be perceived to bias, their work.

Contribution statement MHS designed the study, performed the analyses and wrote the manuscript. PP, HCL, EP and JK contributed to the study design and analysis and critically reviewed the manuscript. DCC conceptualised the study, contributed to the study design and analysis, and critically reviewed the manuscript. All authors approved the final manuscript as submitted. MHS and DCC are the guarantors of this work and, as such, had full access to all the data in the study and take responsibility for the integrity of the data and accuracy of the data analysis.

\section{References}

1. Weyer C, Hanson RL, Tataranni PA, Bogardus C, Pratley RE (2000) A high fasting plasma insulin concentration predicts type 2 diabetes independent of insulin resistance: evidence for a 
pathogenic role of relative hyperinsulinemia. Diabetes 49(12): 2094-2101. https://doi.org/10.2337/diabetes.49.12.2094

2. Goodarzi MO, Cui J, Chen YD, Hsueh WA, Guo X, Rotter JI (2011) Fasting insulin reflects heterogeneous physiological processes: role of insulin clearance. Am J Physiol Endocrinol Metab 301(2):E402-E408. https://doi.org/10.1152/ajpendo.00013. 2011

3. Tokarz VL, MacDonald PE, Klip A (2018) The cell biology of systemic insulin function. J Cell Biol 217(7):2273-2289. https:// doi.org/10.1083/jcb.201802095

4. Duckworth WC, Bennett RG, Hamel FG (1998) Insulin degradation: progress and potential. Endocr Rev 19(5):608-624. https://doi. org/10.1210/edrv.19.5.0349

5. DeFronzo R (1988) Lilly lecture 1987 . The triumvirate: beta-cell, muscle, liver. A collusion responsible for NIDDM. Diabetes 37(6): 667-687. https://doi.org/10.2337/diab.37.6.667

6. Weyer C, Bogardus C, Mott DM, Pratley RE (1999) The natural history of insulin secretory dysfunction and insulin resistance in the pathogenesis of type 2 diabetes mellitus. J Clin Invest 104(6):787794. https://doi.org/10.1172/JCI7231

7. Meistas MT, Margolis S, Kowarski AA (1983) Hyperinsulinemia of obesity is due to decreased clearance of insulin. Am J Phys 245(2):E155-E159. https://doi.org/10.1152/ajpendo.1983.245.2. E155

8. Jung SH, Jung CH, Reaven GM, Kim SH (2018) Adapting to insulin resistance in obesity: role of insulin secretion and clearance. Diabetologia 61(3):681-687. https://doi.org/10.1007/s00125-0174511-0

9. Jones CN, Pei D, Staris P, Polonsky KS, Chen YD, Reaven GM (1997) Alterations in the glucose-stimulated insulin secretory doseresponse curve and in insulin clearance in nondiabetic insulinresistant individuals. J Clin Endocrinol Metab 82(6):1834-1838. https://doi.org/10.1210/jcem.82.6.3979

10. Ader M, Stefanovski D, Kim SP et al (2014) Hepatic insulin clearance is the primary determinant of insulin sensitivity in the normal dog. Obesity (Silver Spring) 22(5):1238-1245. https://doi.org/10. 1002/oby.20625

11. Bergman RN, Piccinini F, Kabir M, Kolka CM, Ader M (2019) Hypothesis: role of reduced hepatic insulin clearance in the pathogenesis of type 2 diabetes. Diabetes 68(9):1709-1716. https://doi. org/10.2337/db19-0098

12. Watada H, Tamura $Y$ (2017) Impaired insulin clearance as a cause rather than a consequence of insulin resistance. J Diabetes Investig 8(6):723-725. https://doi.org/10.1111/jdi.12717

13. Kabir M, Catalano KJ, Ananthnarayan S et al (2005) Molecular evidence supporting the portal theory: a causative link between visceral adiposity and hepatic insulin resistance. Am J Physiol Endocrinol Metab 288(2):E454-E461. https://doi.org/10.1152/ ajpendo.00203.2004

14. Lee CC, Haffner SM, Wagenknecht LE et al (2013) Insulin clearance and the incidence of type 2 diabetes in Hispanics and African Americans: the IRAS Family Study. Diabetes Care 36(4):901-907. https://doi.org/10.2337/dc12-1316

15. Knowler WC, Bennett PH, Hamman RF, Miller M (1978) Diabetes incidence and prevalence in Pima Indians: a 19-fold greater incidence than in Rochester, Minnesota. Am J Epidemiol 108(6):497505. https://doi.org/10.1093/oxfordjournals.aje.a112648

16. Lillioja S, Mott DM, Spraul M et al (1993) Insulin resistance and insulin secretory dysfunction as precursors of non-insulindependent diabetes mellitus. Prospective studies of Pima Indians. N Engl J Med 329(27):1988-1992. https://doi.org/10.1056/ NEJM199312303292703

17. Genuth S, Alberti KG, Bennett P et al (2003) Follow-up report on the diagnosis of diabetes mellitus. Diabetes Care 26(11):3160 3167. https://doi.org/10.2337/diacare.26.11.3160
18. Knowler WC, Saad MF, Pettitt DJ, Nelson RG, Bennett PH (1993) Determinants of diabetes mellitus in the Pima Indians. Diabetes Care 16(1):216-227. https://doi.org/10.2337/diacare.16.1.216

19. Goldman RF, Buskirk ER (1961) Body volume measurement by underwater weighing: description of a method. Techniques for measuring body composition. National Academy of ScienceNational Research Council, Washington, DC, pp. 78-89

20. Tataranni PA, Ravussin E (1995) Use of dual-energy x-ray absorptiometry in obese individuals. Am J Clin Nutr 62(4):730-734. https://doi.org/10.1093/ajen/62.4.730

21. Schwartz MW, Boyko EJ, Kahn SE, Ravussin E, Bogardus C (1995) Reduced insulin secretion: an independent predictor of body weight gain. J Clin Endocrinol Metab 80(5):1571-1576. https://doi. org/10.1210/jcem.80.5.7745002

22. Chen M, Porte D (1976) The effect of rate and dose of glucose infusion on the acute insulin response in man. J Clin Endocrinol Metab 42(6):1168-1175. https://doi.org/10.1210/jcem-42-6-1168

23. Lillioja S, Mott DM, Howard BV et al (1988) Impaired glucose tolerance as a disorder of insulin action. Longitudinal and crosssectional studies in Pima Indians. N Engl J Med 318(19):12171225. https://doi.org/10.1056/NEJM198805123181901

24. DeFronzo RA, Tobin JD, Andres R (1979) Glucose clamp technique: a method for quantifying insulin secretion and resistance. Am J Phys 237(3):E214-E223. https://doi.org/10.1152/ajpendo. 1979.237.3.E214

25. Steele R (1959) Influences of glucose loading and of injected insulin on hepatic glucose output. Ann N Y Acad Sci 82:420-430. https://doi.org/10.1111/j.1749-6632.1959.tb44923.x

26. Castillo MJ, Scheen AJ, Letiexhe MR, Lefèbvre PJ (1994) How to measure insulin clearance. Diabetes Metab Rev 10(2):119-150. https://doi.org/10.1002/dmr.5610100205

27. Goodarzi MO, Taylor KD, Guo X et al (2005) Variation in the gene for muscle-specific AMP deaminase is associated with insulin clearance, a highly heritable trait. Diabetes 54(4):1222-1227. https://doi.org/10.2337/diabetes.54.4.1222

28. Kim MK, Reaven GM, Chen YD, Kim E, Kim SH (2015) Hyperinsulinemia in individuals with obesity: role of insulin clearance. Obesity (Silver Spring) 23(12):2430-2434. https://doi.org/ 10.1002/oby. 21256

29. Kotronen A, Juurinen L, Tiikkainen M, Vehkavaara S, YkiJarvinen H (2008) Increased liver fat, impaired insulin clearance, and hepatic and adipose tissue insulin resistance in type 2 diabetes. Gastroenterology 135(1):122-130. https://doi.org/10.1053/j.gastro. 2008.03.021

30. Leibiger IB, Leibiger B, Berggren P-O (2008) Insulin signaling in the pancreatic $\beta$-cell. Annu Rev Nutr 28(1):233-251. https://doi. org/10.1146/annurev.nutr.28.061807.155530

31. Anderwald C, Tura A, Grassi A et al (2011) Insulin infusion during normoglycemia modulates insulin secretion according to wholebody insulin sensitivity. Diabetes Care 34(2):437-441. https://doi. org/10.2337/dc10-1137

32. Herbert V, Lau KS, Gottlieb CW, Bleicher SJ (1965) Coated charcoal immunoassay of insulin. J Clin Endocrinol Metab 25(10): 1375-1384. https://doi.org/10.1210/jcem-25-10-1375

33. Yalow RS, Berson SA (1996) Immunoassay of endogenous plasma insulin in man. Obes Res 4(6):583-600. https://doi.org/10.1002/j. 1550-8528.1996.tb00274.x

34. Lin DY, Wei LJ, Ying Z (1993) Checking the Cox model with cumulative sums of martingale-based residuals. Biometrika 80(3): 557-572. https://doi.org/10.2307/2337177

35. Lin DY, Fleming TR, De Gruttola V (1997) Estimating the proportion of treatment effect explained by a surrogate marker. Stat Med 16(13):1515-1527. https://doi.org/10.1002/(sici)10970258(19970715)16:13<1515::aid-sim572>3.0.co;2-1

36. Pivovarova O, Bernigau W, Bobbert T et al (2013) Hepatic insulin clearance is closely related to metabolic syndrome components. 
Diabetes Care 36(11):3779-3785. https://doi.org/10.2337/dc121203

37. Amato MC, Vesco R, Vigneri E, Ciresi A, Giordano C (2015) Hyperinsulinism and polycystic ovary syndrome (PCOS): role of insulin clearance. J Endocrinol Investig 38(12):1319-1326. https:// doi.org/10.1007/s40618-015-0372-x

38. Kotronen A, Vehkavaara S, Seppala-Lindroos A, Bergholm R, YkiJarvinen H (2007) Effect of liver fat on insulin clearance. Am J Physiol Endocrinol Metab 293(6):E1709-E1715. https://doi.org/ 10.1152/ajpendo.00444.2007

39. Fosam A, Sikder S, Abel BS et al (2020) Reduced insulin clearance and insulin degrading enzyme activity contribute to hyperinsulinemia in African Americans. J Clin Endocrinol Metab. https://doi.org/10.1210/clinem/dgaa070

40. Piccinini F, Polidori DC, Gower BA, Bergman RN (2017) Hepatic but not extrahepatic insulin clearance is lower in African American than in European American women. Diabetes 66(10):2564-2570. https://doi.org/10.2337/db17-0413

41. Jensen MD, Nielsen S, Gupta N, Basu R, Rizza RA (2012) Insulin clearance is different in men and women. Metabolism 61(4):525530. https://doi.org/10.1016/j.metabol.2011.08.009

42. Lorenzo C, Hanley AJ, Wagenknecht LE et al (2013) Relationship of insulin sensitivity, insulin secretion, and adiposity with insulin clearance in a multiethnic population: the insulin Resistance Atherosclerosis study. Diabetes Care 36(1):101-103. https://doi. org/10.2337/dc12-0101
43. Semnani-Azad Z, Johnston LW, Lee C et al (2019) Determinants of longitudinal change in insulin clearance: the Prospective Metabolism and Islet Cell Evaluation cohort. BMJ Open Diabetes Res Care 7(1):e000825. https://doi.org/10.1136/bmjdrc-2019000825

44. Fiorentino TV, Sesti F, Succurro E et al (2018) Higher serum levels of uric acid are associated with a reduced insulin clearance in nondiabetic individuals. Acta Diabetol 55(8):835-842. https://doi.org/ 10.1007/s00592-018-1153-8

45. Ghadieh HE, Russo L, Muturi HT et al (2019) Hyperinsulinemia drives hepatic insulin resistance in male mice with liver-specific Ceacam1 deletion independently of lipolysis. Metabolism 93:3343. https://doi.org/10.1016/j.metabol.2019.01.008

46. Hennes MM, Dua A, Kissebah AH (1997) Effects of free fatty acids and glucose on splanchnic insulin dynamics. Diabetes 46(1):57-62. https://doi.org/10.2337/diab.46.1.57

47. Vozarova B, Stefan N, Lindsay RS et al (2002) High alanine aminotransferase is associated with decreased hepatic insulin sensitivity and predicts the development of type 2 diabetes. Diabetes 51(6): 1889-1895. https://doi.org/10.2337/diabetes.51.6.1889

48. Piccinini F, Bergman RN (2020) The measurement of insulin clearance. Diabetes Care 43(9):2296-2302. https://doi.org/10.2337/ dc20-0750

Publisher's note Springer Nature remains neutral with regard to jurisdictional claims in published maps and institutional affiliations. 